\title{
Der verbraucherrechtliche Unternehmerbegriff
}

Seine Übertragung auf das deutsche HGB nach Vorbild der UGB-Reform in Österreich

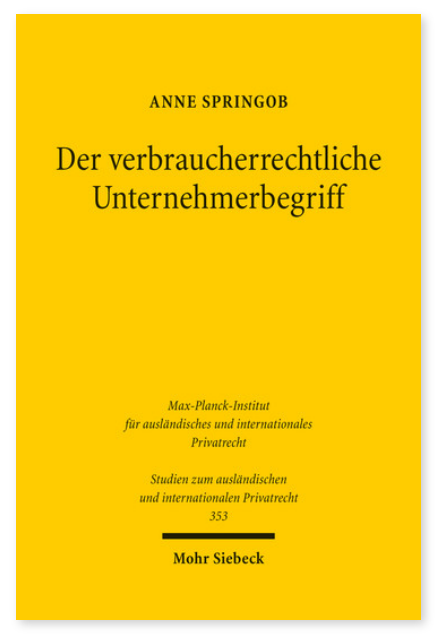

2016. XXI, 296 Seiten. StudIPR 353

ISBN 978-3-16-154150-6

eBook PDF 74,00€

ISBN 978-3-16-154104-9

fadengeheftete Broschur 74,00€
Anne Springob beschäftigt sich mit der Reformbedürftigkeit des handelsrechtlichen Kaufmannsbegriffs und insbesondere mit der Frage, ob bei einer Reform des subjektiven Anwendungsbereichs des HGB auf die österreichische UGB-Reform zurückgegriffen werden könnte und sollte. Ein Blick über den Tellerrand lohnt sich, denn Österreich hat im Jahr 2007 den Kaufmannsbegriff abgeschafft und durch den verbraucherrechtlichen Unternehmerbegriff ersetzt, in einigen Bereichen aber Sonderregeln für Freiberufler und Land- und Forstwirte beibehalten. Nach einer Gegenüberstellung der relevanten Rechtsgebiete in beiden Ländern wird die Reichweite einer möglichen Übertragung der österreichischen UGB-Reform unter besonderer Berücksichtigung der Frage diskutiert, ob die bestehenden Privilegien für Freiberufler und Land- und Forstwirte noch eine Berechtigung haben und welche Gründe dafür sprechen, sie abzubauen.

Anne Springob Geboren 1983; Studium der Rechtswissenschaft an der Universität Münster und der Universitat de Barcelona; LL.M.-Studium (Global Business Law), La Trobe University, Melbourne; Referendariat OLG Düsseldorf (Stammdienststelle Düsseldorf); 2012 zweites Staatsexamen JPA Düsseldorf; 2015 Promotion; derzeit als Rechtsanwältin in Düsseldorf tätig.

Jetzt bestellen:

https://mohrsiebeck.com/buch/der-verbraucherrechtliche-unternehmerbegriff-9783161541506?no_cache=1 order@mohrsiebeck.com

Telefon: $+49(0) 7071-923-17$

Telefax: $+49(0) 7071-51104$ 